\title{
Germplasm Preservation And Propagation; The Foundation Of Agricultural Development -A Review
}

\author{
Nwachukwu, Ifeanyi,; Ndukwe, Okorie k.; Ekaiko, Marshall. U. \\ Department of Biology/Microbiology, Abia State Polytechnic Aba, Abia State.
}

\begin{abstract}
Abstact: The whole set of genetic material of a species of plants is known as germplasm of the organisms. Through various breeding techniques the germplasm of various plant species can be stored or preserved for future plant development. The techniques of gerplasm preservation vary from cryopreservation, slow growth cultures, DNA clones, in-vitro storage, cold storage, super cold storage, field preservation to the use of artificial seeds. The major purpose of germplasm preservation is to preserve rare and endangered species of plants around the globe for future propagation and development; hence germplasm is the foundations of agricultural productions. Today's preservation techniques have been developed on the base of natural occurring phenomena like sporulation, germination, hibernation and adaptation which are found in different animals and in micro organisms. All the simple and sophisticated preservation techniques are today being used in giant projects that are on going.
\end{abstract}

Keywords: Germplasm, Genetic materials, Preservation, Propagation.

\section{Introduction}

All crops, whether traditional varieties selected and harvested by farmers or modern varieties bred by professional plant breeders, descend from wild and improved genetic resources (also called germplasm) collected around the world. Plant selection and breeding do not end once an improved variety is achieved because the challenges facing crop production; pest, pathogens and climates constantly evolve and change (Marshall, 1990). To make crops more resistant to pests and diseases and to improve food supply quality, quantity and variety, modern plant breeders continually seek genetic resources (germplasm) from outside the stocks with which they routinely work.

Since no nation has within its borders the desired spectrum of genetic resources and because valuable genetic resources not yet collected and preserved may be endangered by land use changes in some countries, there is then the need for germplasm preservation and propagation since plant genetic resources are the basis of future agriculture. They include traditional and modern cultivars as well as their wild relatives (Rao, 2004).

\section{Definition}

Germplasm refers to the hereditary materials transmitted to the offspring through the germ cells (Wilkes, 1991). It is the total content of genes that serves as the raw material for the breeder to develop different crops (Duvick, 1982). In other words, germplasm can be defined as living tissue from which new plants can be grown. It can be a seed or another plants part; a leaf, a piece of stem, pollen or even just a few cells that can be turned into a whole plant (Witt, 1985). Germplasm is the living genetic resources such as seeds or tissue that is maintained for the purpose of animal and plant breeding, preservation and other research uses (Williams, 1991). These resources may take the form of seed collections such as seed banks, trees growing in nurseries, animal breeding lines maintained in animal breeding programmes or gene banks etc (Juma, 1989). It contains the information for a species genetic makeup, a valuable natural resource of plant diversity. Germplasm collections can range from collections of wild species to elite, domesticated breeding lines that have undergone extensive human selection. The main objective of germplasm collection is preservation of genetic diversity of a particular plant or genetic stock for its use in the future (Peefers and Calwey, 1988).

\section{Types Of Germplasm}

Germplasm can be organized in six different categories based on their station or advancement in the agroecosystem (Wilkes, 1977; 1991). These include.

- Advanced (Or Elite) Germplasm:

(1) 'Cultivars' or cultivated varieties, which are suitable for planting by farmers, either recently developed cultivars or 'Obsolete' cultivars that are no longer grown.

(2) Advanced breeding materials that breeders combine to produce new cultivars (sometimes referred to as "breeding materials").

- Improved Germplasm: This is any plant material containing one or more traits of interest that have been incorporated by scientific selection or planned crossing. 
- Landraces: These are varieties of crops improved by farmers over many generations without the use of modern breeding techniques. Within a modern breeding programme, landraces are sometimes used for resistance traits and generally required before their genes can be used in a final variety.

- Wild Or Weedy Relatives: Are plants that share a common ancestry with a crop species but have not been domesticated. These plants can serve as another source of resistance traits, but these traits can be very difficult to incorporate on final varieties.

- Genetic Stock: These are mutants or other germplasm with genetic abnormalities that may be used by plant breeders for specific purposes. Genetic stocks are often used for highly sophisticated breeding and basic research.

\section{Modern Plant Breeding}

Generally, plant breeders prefers to work with existing cultivars or advanced breeding materials (sometimes called elite materials), because these adapted sources of material are already highly productive and relatively easy to intimate. But because pests and diseases evolve over times, breeders continually need new and diverse germplasm from outside the standard gene pool to find specific traits to maintain or improve yields. Sometimes as a last resort, breeders rely on landraces and wild relatives of crops, but these generally carry unwanted traits that are linked with a desirable traits gene, making it difficult to incorporate the trait into highyielding cultivars. When used, however, genes from landraces or wild relatives often have had disproportionately large and beneficial impacts. Some breeders also seek and use traits and information from 'genetic stock' which include mutants and other germpalsm with genetic abnormalities.

The advent of biotechnology may expand the scope of desired traits that can be incorporated in new varieties. The use of biotechnological techniques, such as molecular markers, may make it easier to incorporate the beneficial characteristics of landraces and wild relatives of agricultural crops (Juma, 1989). Biotechnology also can be used to incorporate traits from very disparate species. The challenges of developing pest and disease resistance and improvements in yield potential remain the same regardless of whether a plant is conventionally bred or bioengineered.

\section{Benefits Of Germplasm Collection}

Collection of germplasm has been found to yield many advantages and these benefits are outlined below.

1) Cell and tissue culture of many plants species can be cryopreserved and maintained in a viable state for several years and used when required (Goodman, 1990).

2) Plant material from endangered species can be conserved using this method.

3) It is an ideal method for long term conservation of cell cultures producing secondary metabolites such as antibiotics

4) Recalcitrant seeds (seeds which loose their viability on storage) can be maintained for a long period of time.

5) Disease free plants material can be frozen and propagated whenever required.

6) Conservation of somaclonal variations in cultures.

7) Rare germplasms developed by using somatic hybridization and other genetic manipulation techniques can be stored.

8) Pollen conservation for enhancing longevity.

9) Germplasm banks facilitate the exchange of information at international level.

\section{Germplasm Preservation And Propagation}

Through the knowledge of germplasm, various breeding techniques of plants have been developed (Peefers and Calwey, 1988). Hence the storage or preservation of germplasm is important. Conventionally seeds were used to store the germplasm, but in case where seeds cannot be used for regeneration of plants or in case where shoot and root tissue is not stable, it is then important to preserve them. Gremplasm preservation can be done by two broad methods namely "in situ preservation and exsitu preservation" (Alcorn, 1991). In situ preservation includes the organization and / or servicing of natural supplies where species are permitted to stay in maximum environment with the lowest of management. On the other hand, ex situ preservation includes the use of botanic landscapes, field farms, seeds shops and gene financial banks. However, within each type of preservation, there are numerous techniques/mechanisms and associated problems. These are discussed as follows.

$>$ Cryopreservation: The freeze preservation of cells or tissues in liquid nitrogen at $-196^{\circ} \mathrm{C}$ is known as cryopreservation. This technique involves four steps.

a) Freezing: The procedure of freezing may be conducted slowly, rapidly or initial freezing by dropping temperature slowly and followed by a rapid decrease in temperature. In order that the plants are affected by the sudden decrease in temperature, treatment of cells with plant verification solution helps cells and tissue to overcome the harsh temperature. The medium was added with cry protectant like DMSO, glycerol and 
proline to the culture medium to protect cells from injury. The addition of cry protectant protects the cell by prevention of large crystals inside cell, protect from water loss from cell. The frozen cells are stored in a refrigerator containing liquid nitrogen. The temperature of such refrigerator is maintained at or below $130^{\circ} \mathrm{C}$. Organized tissues like shoot tips, somatic and zygotic embryos are usually chosen for storage. Attentively cells can be immobilized in sodium alginate and then cryopreserved.

b) Thawing: Thawing of culture is done in a rapid process. The freeze preserved culture is dipped in a water bath containing water at about $37-40^{\circ} \mathrm{C}$ for 90 seconds. This process is done rapidly so that no ice crystals are formed. The thawed culture is washed several times to remove cryoprotectant. In the recent times, the cryoprotectant is removed by diluting. This is done by fixing the culture along with a cryoprotectant onto a disk and is kept on a suitable medium. The disk is frequently transferred into a fresh medium. This frequent transfer dilutes out the cryoprotectant.

c) Reculture: The culture which is freeze preserved need to be thawed and cultured to bring it back to normal life. The optimum conditions of freeze preserved plants have to be determined for developing a successful reculture. After cryopreservation, some plants tend to show special requirement for growth which was not necessary under normal propagation of the corresponding plants. For example, tomato shoots tips when cryopreserved, thawed and recultured, the culture required some levels of abscisic acid in their medium in order to initiate and develop shoot tip from callus formed.

It has been found that mostly meristematic cells survive cryopreservation than other cells. In parts where the germplasm cannot be stored in seeds or other parts the cryopreservation provides a good option of storage and future usage.

$>$ Slow growth cultures: This is another method that can be used in germplasm preservation and propagation. It involves limiting the conditions of growth so that the culture does not grow and propagate in ordinary pace. This can be achieved by limiting the factors affecting the growth. This provides an attractive alternative to cryopreservative as the procedure is cost effective and simply comparatively. There is also reduction of contamination and gene modification (Reed et al., 1998). The various factors affecting the growth of cultures are temperature, nutrient restriction, growth regulation and osmotic concentration. Other factors that can affect growth of cultures include oxygen concentration, type of culture vessel used as well as restriction of illumination received by cultures.

> DNA clones: The germplasm can also be preserved in DNA segments cloned into appropriate vectors but the process demands high expertise and is costly.

$>$ Artificial seeds: Another mechanism of germplasm preservation is by desiccating embryos and storing it as artificial seeds. This has proved to be an effective technique, but was possible only with somatic embryo and in certain cases by shoot tips. This process of germplasm preservation offers several advantages like cost effective, availability of germplasm of specific plants to propagate, small storage space, and longer terms of storage. In addition, it reduces risks such as cell damage by cryopreservation, and does not involve high technology associated with other methods.

> In-vitro storage: This is another method of germplasm preservation which is now routinely used for germplasm of some crops like cassava. The in-vitro cassava gene bank at CIAT, Colombia, comprises nearly 5000 clones, in an area of 50 square meters, with transfer (subculture) intervals of $12-14$ months (Towill, 1988). While in-vitro storage thus offers some advantage over field genebanks, such as requiring less space and limited labour cost (Towill, 1988), however, the management of large collections remains problematical, due to the requirement for periodic subculture. The possible introduction of genetic variants during culture may be a risk with some types of culture (withers, 1992).

$>$ Cold storage: In this technique, bulbs, tubers and rhizome of certain crops can be stored at $0-15^{\circ} \mathrm{C}$ under high humidity for several months or up to one year. However, it is also a type of short- term storage (Romano and Martins-Loucao, 1999).

$>$ Super-cold storage: This technique allows the embryos, tissues and pollen grains to be stored for long periods in liquid nitrogen at $-196^{\circ} \mathrm{C}$. However, its practical use is yet to be developed as crops require different cooling and thawing treatments and have different viability level.

$>$ Field conservation: Germplasm materials such as fruit trees, potatoes and grasses are grown in nurseries field for preservation. Field nurseries can be maintained at different elevations above sea level.

\section{Conclusion}

Germplasm is the foundation of agricultural production. Regardless of future developments in biotechnology such as gene transfer, tissue culture, etc. practical use of advanced biotechniques is not possible without germplasm. With the rapid loss of germplasm materials nowdays, the gathering and preservation of germplasm take on new urgency and become imperative, because germplasm serves as the raw material for the breeder to develop different crops. This is also possible due to the fact that now there are availability of good physical facilities and equipment. The main objective of germplasm collection is preservation of genetic 
diversity of a particular plant or genetic stock for its use in the future. Gremplasm preservation techniques are not only hope for plant under threat of extinction but also save medicinal and other valuable plants on which lives are dependent.

\section{References}

[1]. Alcorn, J. B. (1991). "Ethics, Economics and Conservation.” In M. Oldfield and J. Alcorn, eds., Biodiversity; Culture, Conservation and Ecodevelopment.Westview Press, Colo. Boulder

[2]. Duvick, D. N. (1982). Genetic diversity in major farm crops on the farm and in reserve. Australian Plant Breeding and Genetics Newsletter. 32: 1-40.

[3]. Gianni, S. and Sottile, F. (2015). In vitro storage of plum germplasm by slow growth. Hort. Sci 42 (2); 61-69.

[4]. Goodman, M. (1990). "Genetic and Germplasm Stocks Worth Conserving." Journal of Heredity 81: 11-16..

[5]. Juma, C. (1989). The Gene Hunters: Biotechnology and the scramble for for seeds. Princetown University Press, Princetown.

[6]. Marshall, D. R. (1990). "Crop Genetic Resources; Current and Emerging Issues.” In A.H D. Brown, M. Cegg. A. Kahler and B. Weir, eds., Plant Population Genetics, Breeding and Genetic Resources Sinauer Associates, Mass, Sunderland.

[7]. Peefers, J. P. and Calwey, N. W. (1988). "Germplasm Collection and Breeding Needs in Europe." Economic Botany 42: 503521.

[8]. Rao, N. K. (2004). Plant genetic resources: Advancing conservation and use through biotechnology .AfricanJournal of Biotechnology. 3: 136-145

[9]. Reed, B. M.; Paynter, C. L.; DeNoma, J. and Chang, Y. J. (1998). Techniques for medium and long-term storage of pear (pyrus L.) genetic resources. Plant Genetic Resources Newsletter. 115: 1-5.

[10]. Romano, A. and Martins-Loucao, M. A. (1999). In vitro cold storage of cork oak shoot cultures. Plant Cell Tissue Organ Culture. 59: $155-157$.

[11]. Towill, L. E. (1988). Genetic considerations for germplasm preservation of clonal materials. Horticultural Sciences.23: $77-97$.

[12]. Wilkes, G. (1977). "The World's Crop Plant Germplasm: An Endangered Resource.” Bulletin Atomic Scientist 38: 8-16.

[13]. Wilkes, G. (1991). "In Situ Conservation of Agricultural Systems." In M. Oldfield and J. Alcorn, eds. Biodiversity; Culture, Conservation and Ecodevelopment. Westview Press, Colo. Boulder.

[14]. Williams, J. T. (1991). "Plant Genetic Resources: Some New Directions." Advances in Agronomy 45: 61-91.

[15]. Witt, S. C. (1985). Brief Book: Biotechnology and Genetic Diversity. Centre for Scientific Information, San Francisco. 